\title{
Wood Fiber-reinforced Polylactic Acid Sheets Enabled by Papermaking
}

\author{
Yang Zhao, ${ }^{\mathrm{a}}$ Qinpeng Shen, ${ }^{\mathrm{a}}$ Y uanxin Duan, ${ }^{\mathrm{a}}$ Shuyin Wu, ${ }^{\mathrm{b}}$ Ping Lei, ${ }^{\mathrm{a}}$ Liu Yang, ${ }^{\mathrm{a}, *}$ \\ Yunhua Qin, ${ }^{\mathrm{a}}$ and Fei Yang ${ }^{\mathrm{b}, *}$
}

\begin{abstract}
Polylactic acid is a biodegradable thermoplastic polyester derived from renewable polysaccharides. In this work, softwood fibers were used to reinforce the paper sheet made from polylactic acid fibers, thus addressing the challenges regarding low density, rough surface, and weak strength. The impact of wood fibers and calendering on the physical properties (density, roughness, tensile strength, and folding endurance) of the composite paper were identified. Furthermore, the morphology of papers with different fiber contents and those that had been calendered was characterized with a scanning electron microscope. The use of wood fibers resulted in the improvement of the physical properties of the polylactic acid paper, and the enhanced refining of wood fibers had a favorable role in improving paper density, smoothness, and mechanical strength. The tensile index increased $37.9 \%$ when the beating degree of wood fibers increased from 25 to $60^{\circ} \mathrm{SR}$. After calendering, the density, smoothness, tensile strength, folding endurance, and air barrier property of the paper were improved $60.2 \%, 45.8 \%, 15.5 \%, 148.1 \%$, and $79.4 \%$, respectively. The calendering-based papermaking process involving the combined use of wood fibers and polylactic acid fibers would be a promising strategy for designing composite materials for tailorable end-uses.
\end{abstract}

Keywords: Polylactic acid fiber; Wood fiber; Calendering; Papermaking; Mechanical property

Contact information: a: R\&D Center, China Tobacco Yunnan Industrial Co., Ltd., Kunming 650231, China; b: State Key Laboratory of Pulp and Paper Engineering, South China University of Technology, Guangzhou 510640, China; *Corresponding authors: liuyang929@126.com; yangfei@ scut.edu.cn

\section{INTRODUCTION}

Today, synthetic plastics are indispensable. The manufacture of plastics relies on unsustainable petroleum resources, and these products cannot be degraded in the natural environment for hundreds of years after being disposed. It has been reported that about 9.5 million tons of plastic waste is discharged into the ocean annually (Lau et al. 2020), which has a great impact on human health and ecology. Therefore, the utilization of environmentally friendly, biodegradable, and renewable plastic materials has attracted much attention. Polylactic acid (PLA) is one example of these materials. It is a type of thermoplastic linear aliphatic polyester that can be made from natural carbohydrate sources (Nagarajan et al. 2016). Polylactic acid has excellent mechanical properties and biocompatibility and can be made into products of various shapes via extrusion, injection molding, blow molding, weaving, and other methods (Jamshidian et al. 2010; Singhvi et al. 2019).

Among the preparation methods of polylactic acid end products mentioned above, papermaking, or wet-laid forming (where the length of fibers used is much greater than 3 $\mathrm{mm}$ ), is a promising way for processing polylactic acid fibers into flexible sheet materials. 
Papermaking is a versatile strategy of converting fibers into assembled structures (Tyagi et al. 2018; Naithani et al. 2020; Zambrano et al. 2020). Compared with other methods, papermaking has the advantages of mature technology, continuous production, high yield, and low cost. However, due to the lack of hydroxyl groups on the polylactic acid surface, polylactic acid fibers cannot be combined together by hydrogen bonds. Moreover, polylactic acid fiber is stiffer and more brittle than cellulose fiber. These characteristics result in the porous structure, rough surface, and weak mechanical properties (tensile strength, tearing strength, and folding endurance) of polylactic acid paper. One approach for overcoming these drawbacks is to introduce cellulose fiber into a polylactic acid sheet. Cellulose fiber is one of the most abundant natural resources. It is inexpensive, renewable, fully degradable, and biocompatible. By the papermaking method, the cellulose fibers and polylactic acid fibers are blended and dispersed in an aqueous medium to produce a uniform composite sheet, in which the cellulose fibers form a robust network by hydrogen bonds. Polylactic acid fibers (or other fibers) can be embedded in the network by entanglement. The enhancement in the tightness and mechanical strength is enabled by the following facts. First, the aqueous medium can provide effective dispersion of cellulosic substance and polylactic acid (Nakagaito et al. 2009; Larsson et al. 2012). Second, as the water evaporates from the wet sheet web during the drying, the fibers are drawn together by the surface tension of water, which promotes the contact between fibers and the formation of hydrogen bonds (Hubbe 2006). Wang et al. (2015) successfully prepared polylactic acid paper reinforced by bamboo fiber through a papermaking process. Their research showed that adding bamboo fiber to a polylactic acid fiber slurry could improve the mechanical properties (tensile index, burst index, and tear index) of the prepared polylactic acid composite, and the density of polylactic acid paper increased at the high bamboo fiber content.

Research studies have considered the effects of different treatment of polylactic acid and cellulose fiber on the physical strength of polylactic acid/cellulose fiber composite paper (Cao and Chen 2010; Yang et al. 2018; Raunio et al. 2020). Cao and Chen (2010) used a laboratory Hollander beater to refine the polylactic acid fiber and studied the influence on the polylactic acid fiber morphology. Raunio et al. (2020) showed that the effect of ultrasonication on the physical structure and surface properties of polylactic acid fiber is similar to that of beating, namely reducing the fibril length and making its surface more hydrophilic and anionic. Yang et al. (2018) pretreated the bamboo fiber and polylactic acid with polyvinyl alcohol. By such processing they successfully enhanced the compatibility and adhesion between bamboo fiber and polylactic acid, thus improving the physical strength of polylactic acid/bamboo composite paper. However, these treatments could not effectively enhance the mechanical strength of the prepared composite paper (tensile index improved less than 25\%), and as a result of ultrasonication the mechanical strength could even decline. Besides, as far as the authors know, the effect of the beating of cellulose fiber on composite paper has been neglected and remains to be further understood.

In addition to beating, thermoforming is another common and essential treatment to produce polylactic acid (composite) sheet with excellent physical strength (Sousa et al. 2019; Yang et al. 2019; Raunio et al. 2020). This process usually involves relatively high temperature (above $160{ }^{\circ} \mathrm{C}$ ) and pressure (around $5 \mathrm{MPa}$ ) and may last from $30 \mathrm{~s}$ to several minutes. Polylactic acid fibers melt and flow under the pressure during the thermoforming, then fill the gaps between fibers and coat cellulose fiber surface. Therefore, the fibers can form a strong adhesion by dispersion forces and a riveted joint effect, finally resulting in a 
denser structure and material with better mechanical properties. In previous studies, a plate hot-pressing machine was used to implement the thermoforming, which makes the thermoforming a batch process, requiring time to heat up and cool down for every thermocompression. That type of thermoforming might not suitable for industrial manufacture.

In this study, bleached softwood fibers were used to improve the brittleness, roughness, and mechanical robustness (tensile strength and folding endurance) of polylactic acid paper, and the polylactic acid/wood fiber composite papers were prepared by a papermaking method. The physical properties of the composite papers, including density, tensile strength, folding endurance, and surface roughness were determined. The effects of the content and beating degree of wood fiber were considered. Finally, the thermoforming treatment was performed using a laboratory rolling calender, and its impact on the structure and physical properties of the composite paper were evaluated. Compared with the hot press used in previous studies, rolling calendering has the advantages of rapid process (less than $0.5 \mathrm{~s}$ for every treated paper), energy saving, and more suitable for largescale production in the paper industry.

\section{EXPERIMENTAL}

\section{Materials and Methods}

Bleached softwood kraft pulp was produced by Arauco (Santiago, Chile). The "softwood fiber" or "wood fiber" below refers to the softwood kraft pulp.

Polylactic acid fiber was supplied by Haining Sprutop Chemical Technology Co., Ltd. (Zhejiang, China). Its glass transition temperature $\left(T_{\mathrm{g}}\right)$ and melting point are $69.0{ }^{\circ} \mathrm{C}$ and $157.2^{\circ} \mathrm{C}$, respectively, with an average length of $6 \mathrm{~mm}$ and an average diameter of 1.3 $\mu \mathrm{m}$ on average.

\section{Beating of wood pulp}

Using a Mark VI type PFI refiner (Hamjern Maskjn, Hamar, Norway), the wood pulp samples were refined to different beating degrees of $25^{\circ} \mathrm{SR}, 30^{\circ} \mathrm{SR}, 35^{\circ} \mathrm{SR}, 40{ }^{\circ} \mathrm{SR}$, $45^{\circ} \mathrm{SR}, 50^{\circ} \mathrm{SR}, 55^{\circ} \mathrm{SR}$, and $60^{\circ} \mathrm{SR}$, according to the standard TAPPI T248 sp-00 (2000).

\section{Preparation of composite paper}

The polylactic acid fiber and wood fiber were blended into water to from a suspension with a consistency of $0.2 \%$ at ambient temperature (around $25{ }^{\circ} \mathrm{C}$ ), then dispersed by a deflaker. The polylactic acid/wood fiber composite papers were prepared by a handsheet former (MESSMER 255; Testing Machines, Inc., New Castle, DE, USA) according to TAPPI T205 sp-18 (2018). The wet papers were dried at $105{ }^{\circ} \mathrm{C}$ for $15 \mathrm{~min}$ using a rapid sheet dryer (ABB AB/L\&W, Kista, Sweden). The target basis weight of the paper was set to $80 \mathrm{~g} / \mathrm{m}^{2}$. There were two groups of paper samples prepared for this study. One group of paper samples was made of $40{ }^{\circ} \mathrm{SR}$ wood fibers and polylactic acid fibers with different dry basis mass ratios ranging from 0:10 to 10:0 (wood fiber to polylactic acid fiber). These samples were labeled as WF-0, WF-10, WF-20, .., WF-100, where the numbers represent the mass fraction of wood fiber in the material. The other group of paper samples was composed of $70 \mathrm{wt} \%$ polylactic acid fibers and $30 \mathrm{wt} \%$ wood fibers of different beating degrees. These samples were labeled as B-25, B-30, B-35, B-40, B-45, B-55, and B-60, where the numbers indicate the beating degrees of wood fiber used. 
Some composite papers containing $50 \mathrm{wt} \%$ wood fibers with $40^{\circ} \mathrm{SR}$ beating degree were selected to subject a calendering process, which was conducted on a laboratory rolling calender (Labor Kalander S-CA5/300, Sumet Messtechnik, Denklingen, Germany) with a steel-steel nip. During the calendering, the rolls rotated with a linear velocity of $5 \mathrm{~m} / \mathrm{min}$ (creeping speed). The temperature and nip pressure of calendering were set to $130{ }^{\circ} \mathrm{C}$ and $15 \mathrm{~N} / \mathrm{mm}$ (linear pressure), respectively, because higher temperature would cause the papers to stick to the rolls, bringing operational difficulties.

\section{Characterization}

The surface morphology of the composite papers with different fiber contents (10 $\mathrm{wt} \%, 40 \mathrm{wt} \%, 50 \mathrm{wt} \%$, and $90 \mathrm{wt} \%$ ) and the calendered papers was observed by a scanning electron microscope (SEM; Merlin, Zeiss, Oberkochen, Germany) with an acceleration voltage of $5.0 \mathrm{kV}$. All samples were roughly cut into a $1 \mathrm{~cm} \times 1 \mathrm{~cm}$ square, then sputtercoated with a layer of gold (SC 7610 sputter coater, Fisons Instruments, East Sussex, UK) prior to the SEM observation.

Before the determination of physical properties, all specimens were placed in a constant temperature and humidity room with a relative humidity of $50 \% \pm 2 \%$ and a temperature of $23{ }^{\circ} \mathrm{C} \pm 1{ }^{\circ} \mathrm{C}$ for $24 \mathrm{~h}$. The tensile strength and folding endurance of specimens were measured using a tensile strength tester (L\&W CE062, Kista, Sweden) and an MIT type folding endurance tester (MIT/U21B, Tinius Olsen, Horsham, PA, USA), according to the standards TAPPI T404 (2003) and TAPPI T511 (2013), respectively. The tensile index is calculated as the tensile strength divided by the basis weight of the paper. For the foldability test, the specimen was cut into a strip, pulled by a clip with a constant force of $9.8 \mathrm{~N}$, and then folded to $135^{\circ}$ repetitively at 175 folds/min until it was broken. The folding endurance was counted as the number of double folds.

The surface roughness of the composite papers as-prepared was measured by the air leak method using a Parker print-surf (PPS) roughness tester (CE165, L\&W, Kista, Sweden), according to the TAPPI T555 (1999) standard. The clamping pressure of the apparatus was set to $1 \mathrm{MPa}$. All samples were tested multiple times at different points on the surface. The mean values were taken as the final results.

The air permeability of the calendered and uncalendered composite papers was measured by a paper air permeance tester (L\&W 166, Kista, Sweden), according to the ISO 5636-5 (2013) standard.

To reveal the effects of the beating degree and amount of wood fibers on the physical properties of composite paper, various linear regression analyses were implemented using Origin 8.0 software (Microcal Software, Northampton, MA).

\section{RESULTS AND DISCUSSION}

\section{Role of Wood Fiber Amount in Tuning the Physical Properties of Composite Paper}

The thickness, density, bulk, and PPS roughness of the composite papers made from different fiber furnishes are shown in Table 1, where the density represents the apparent density of the sample, determined by dividing the thickness by the basis weight, and the figures in "bulk" column are the inverses of densities, which represent the space occupied by the unit mass of the composites. 
Table 1. Thickness, Density, Bulk, and Roughness of the Composite Papers Containing Different Amounts of Wood Fibers

\begin{tabular}{|c|c|c|c|c|}
\hline Sample & $\begin{array}{c}\text { Thickness } \\
(\mu \mathrm{m})\end{array}$ & $\begin{array}{c}\text { Density } \\
\left(\mathrm{g} / \mathrm{cm}^{3}\right)\end{array}$ & $\begin{array}{c}\text { Bulk } \\
\left(\mathrm{cm}^{3} / \mathrm{g}\right)\end{array}$ & $\begin{array}{c}\text { PPS Roughness } \\
(\mu \mathrm{m})\end{array}$ \\
\hline WF-0 & 495.7 & 0.161 & 6.22 & 9.83 \\
\hline WF-10 & 397.2 & 0.193 & 5.18 & 9.54 \\
\hline WF-20 & 387.7 & 0.205 & 4.88 & 9.14 \\
\hline WF-30 & 364.6 & 0.208 & 4.80 & 8.57 \\
\hline WF-40 & 311.4 & 0.255 & 3.92 & 8.00 \\
\hline WF-50 & 299.0 & 0.269 & 3.71 & 7.81 \\
\hline WF-60 & 261.8 & 0.307 & 3.26 & 7.41 \\
\hline WF-70 & 236.9 & 0.341 & 2.94 & 7.08 \\
\hline WF-80 & 187.6 & 0.426 & 2.35 & 6.96 \\
\hline WF-90 & 155.8 & 0.512 & 1.95 & 6.50 \\
\hline WF-100 & 123.8 & 0.590 & 1.69 & 5.75 \\
\hline
\end{tabular}

It can be seen from Table 1 that as the content of wood fiber grows from $0 \mathrm{wt} \%$ to $100 \mathrm{wt} \%$, the thickness, bulk, and roughness of the composite papers decrease while the density increases. The data points of bulk in Fig. 1a are almost on a straight line, and so are the data points of roughness in Fig. 1b, indicating the strong linear relationships between the bulk, roughness, and the mass fraction of wood fiber. The behaviors of bulk and roughness are akin to that described by the linear rule of mixtures, which predicts that a measured quantity of "mixture" should be the weighted means of that measured quantity of pure components (Venkateshwaran et al. 2012; Akinbade and Harries 2021). Linear regression was performed on these data, and the results are shown in Table 2.
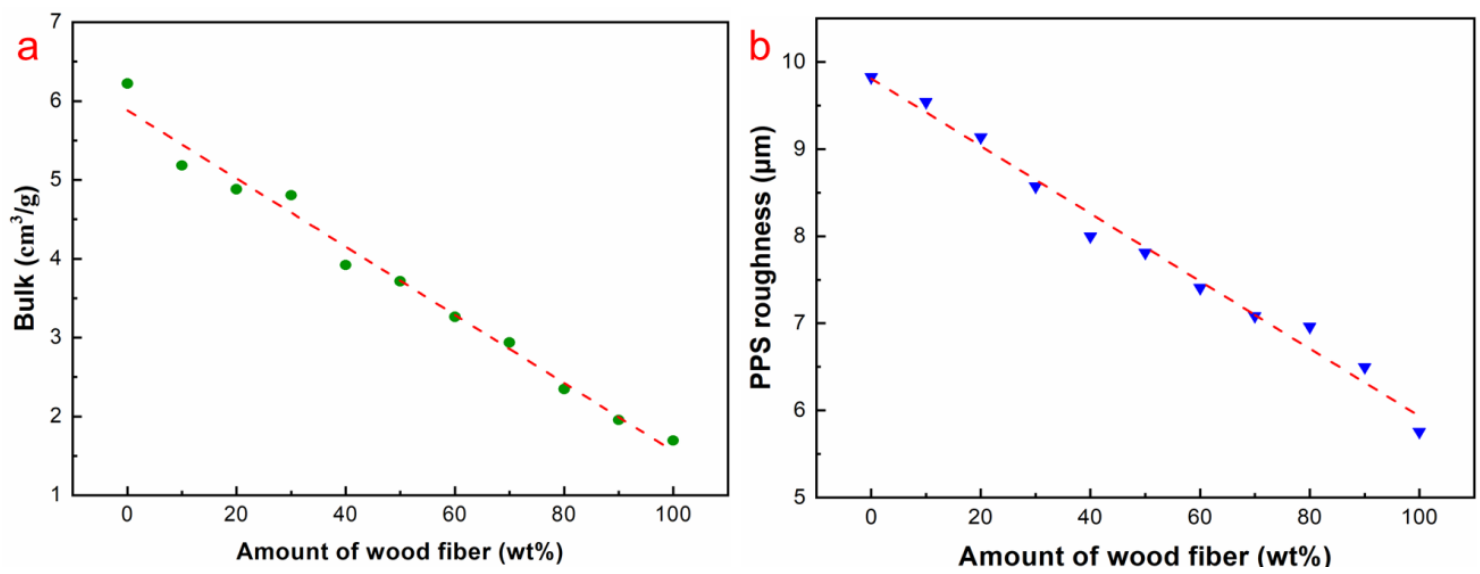

Fig. 1. Bulk (a) and PPS roughness (b) of polylactic acid paper, composite paper, and wood fiber paper

Table 2. Results of Linear Regression Analysis of Bulk and PPS Roughness

\begin{tabular}{|c|c|c|}
\hline $\begin{array}{c}\text { Regression and } \\
\text { Coefficient of } \\
\text { Determination }\end{array}$ & Bulk & PPS Roughness \\
\hline $\mathrm{A}$ & -0.0432 & -0.0388 \\
\hline $\mathrm{B}$ & 5.8799 & 9.8088 \\
\hline $\mathrm{R}^{2}$ & 0.9837 & 0.9845 \\
\hline
\end{tabular}


The paper made of $100 \mathrm{wt} \%$ polylactic acid fibers had the greatest bulk and roughness, which reveals the puffy structure of polylactic acid paper and the weak bonding between polylactic acid fibers. Using the density of polylactic acid paper and wood fiber paper, it can be estimated that the porosity of polylactic acid paper was $87.1 \%$ and wood fiber paper was $61.9 \%$ by Eq. 1 below,

$$
\phi=\frac{\left(V-V_{f}\right)}{V}=1-\frac{\rho}{\rho_{f}}
$$

where the $\Phi$ is the porosity of the paper sheet $(\%), V$ is the volume of the paper $\left(\mathrm{cm}^{3}\right), V_{\mathrm{f}}$ is the volume of fiber $\left(\mathrm{cm}^{3}\right), \rho$ is the apparent density of the paper $\left(\mathrm{g} / \mathrm{cm}^{3}\right)$, and $\rho_{\mathrm{f}}$ is the density of the fibers $\left(\mathrm{g} / \mathrm{cm}^{3}\right)$, which were $1.550 \mathrm{~g} / \mathrm{cm}^{3}$ for cellulose (Lindsay and Brady 1993), and $1.240 \mathrm{~g} / \mathrm{cm}^{3}$ for polylactic acid fiber (Rungiah et al. 2017). The difference between the porosity of polylactic acid papers and wood fiber papers might be because polylactic acid fibers are much stiffer than wood fibers, cannot be fibrilated by the beating process, and the lack of hydroxyl groups, which prevents the polylactic acid fibers from entangling and establishing bonding between each other. The porosities of composite papers made of these two kind fibers can be calculated by the Eq. 2,

$$
\phi=1-\rho\left(\frac{w_{W F}}{\rho_{W F}}+\frac{w_{P L A}}{\rho_{P L A}}\right)
$$

where $w \mathrm{WF}, w \mathrm{PLA}, \rho \mathrm{WF}$, and $\rho_{\mathrm{PLA}}$ are the mass fraction $(\%)$ and density $\left(\mathrm{g} / \mathrm{cm}^{3}\right)$ of wood fibers and polylactic acid, respectively. The results are shown in the Fig. 2, where the porosity of the papers decreased as the wood fiber content increased, which indicated that the wood fibers present in the composite papers formed a more compact three-dimensional network, successfully improved the density.

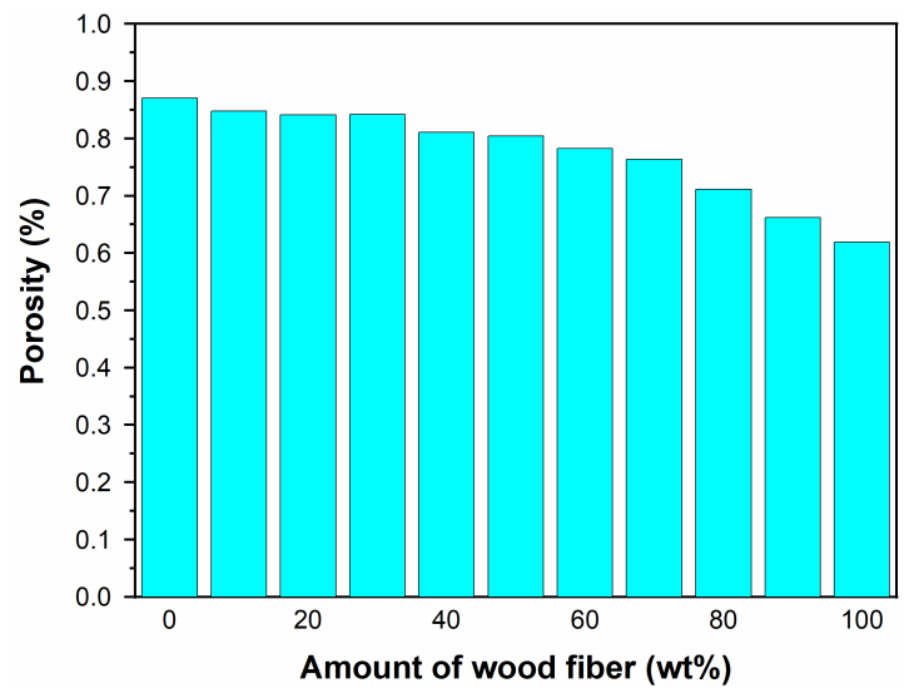

Fig. 2. Porosity of polylactic acid paper, composite papers, and wood fiber paper

The tensile strength, tensile index, and folding endurance of the composite papers made of different amount of wood fiber are shown in Table 3. The horizontal lines mean missing data, because these mechanical strengths of the corresponding materials were too weak to be determined by the apparatus used in this study. 
Table 3. Tensile Strength, Tensile Index, and Folding Endurance of the Composite Papers Containing Different Wood Fiber Amount

\begin{tabular}{|c|c|c|c|}
\hline Sample & $\begin{array}{c}\text { Tensile Strength } \\
(\mathrm{N} / \mathrm{m})\end{array}$ & $\begin{array}{c}\text { Tensile Index } \\
(\mathrm{N} \cdot \mathrm{m} / \mathrm{g})\end{array}$ & $\begin{array}{c}\text { Folding Endurance } \\
\text { (times) }\end{array}$ \\
\hline WF-0 & - & - & - \\
\hline WF-10 & - & - & - \\
\hline WF-20 & 419 & 5.28 & - \\
\hline WF-30 & 804 & 10.62 & 1.0 \\
\hline WF-40 & 1365 & 17.26 & 4.1 \\
\hline WF-50 & 1690 & 21.20 & 8.3 \\
\hline WF-60 & 2063 & 25.78 & 25.0 \\
\hline WF-70 & 2692 & 33.36 & 66.4 \\
\hline WF-80 & 3377 & 42.30 & 283.8 \\
\hline WF-90 & 3477 & 43.61 & 657.6 \\
\hline WF-100 & 4445 & 60.95 & 774.7 \\
\hline
\end{tabular}

As shown in Figs. 3a and 3b, the tensile index and folding endurance of composite papers increased as the increase of the wood fiber content, and the wood fiber papers possessed the highest tensile index and folding endurance. The improvement in mechanical properties was attributed to the long and flexible softwood fibers added to materials, which had the ability to establish a strong hydrogen bonding networks that can disperse, conduct and withstand the tension and shear forces imposed on the composites. The more softwood fibers added to the composites, the more hydrogen bonding networks were formed, and the better the mechanical properties of composites obtained.
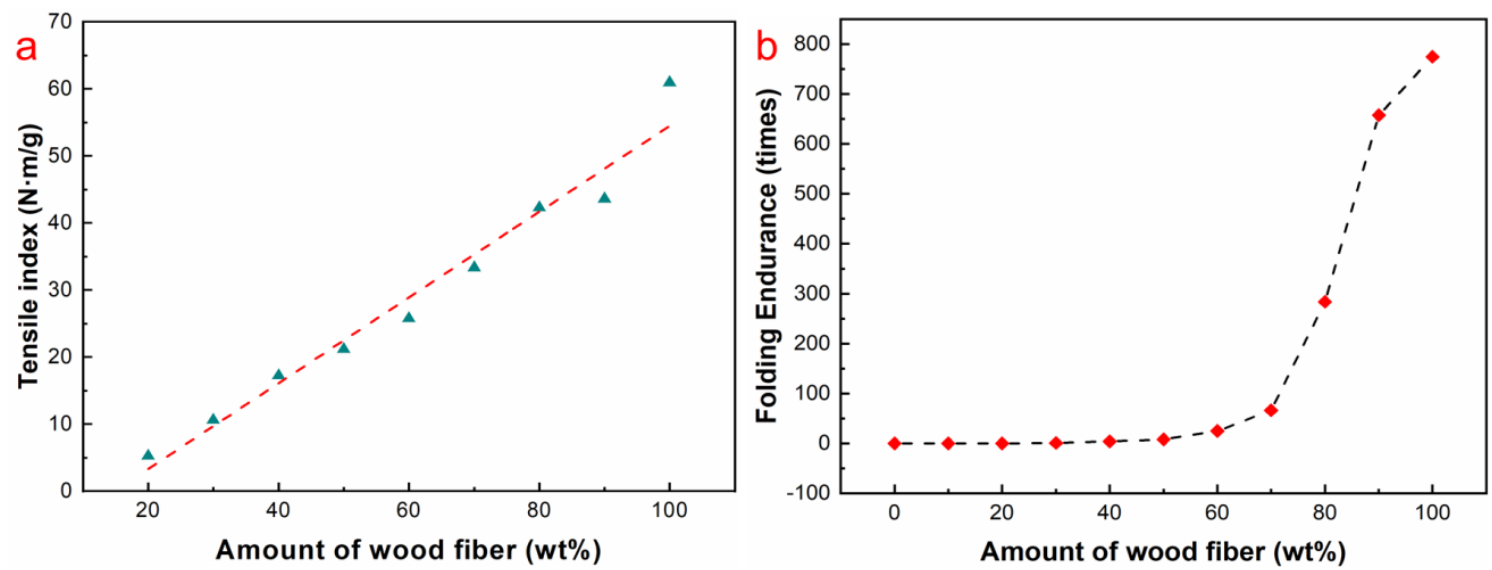

Fig. 3. Tensile index (a) and folding endurance (b) of polylactic acid paper, composite papers, and wood fiber paper

Table 4. Results of Linear Regression Analysis of Tensile Index

\begin{tabular}{|c|c|}
\hline $\begin{array}{c}\text { Regression and } \\
\text { Coefficient of } \\
\text { Determination }\end{array}$ & Tensile Index \\
\hline $\mathrm{A}$ & -9.4605 \\
\hline $\mathrm{B}$ & 0.6381 \\
\hline $\mathrm{R}^{2}$ & 0.9672 \\
\hline
\end{tabular}


However, as the wood fiber content increased, the increase in tensile index and folding endurance were clearly different from each other. The change of tensile index followed the linear rule of mixtures, and linear regression was performed on these data to show this point, of which results are shown in Table 4. Meanwhile, the change in folding endurance was similar to an exponential growth. The folding endurance increased relatively slowly at the beginning and grew faster as the wood fiber content was close to $100 \mathrm{wt} \%$. These two different change patterns might emerge from the different formation mechanisms for the mechanical properties of paper.

Therefore, the introduction of wood fiber into polylactic acid papers improved the density, smoothness, compactness, and mechanical strengths of the composite papers.

\section{Effect of Beating Degree of Wood Fibers on the Physical Properties of the Composite Paper}

The thickness, density, bulk, and PPS roughness of the composite papers made from wood fibers with different beating degrees are shown in Table 5. As shown in Table 5, the beating degree of wood fiber show a positive impact on the density of the composite papers, which is reflective of the fact that the bulk of the composite papers reduced from 5.02 $\mathrm{cm}^{3} / \mathrm{g}$ to $4.37 \mathrm{~cm}^{3} / \mathrm{g}$ as the beating degree of the wood fiber increased from $30{ }^{\circ} \mathrm{SR}$ to $60{ }^{\circ} \mathrm{SR}$.

Table 5. Thickness, Density, Bulk, and Roughness of the Composite Papers Made from 50 wt\% Wood Fiber with Different Beating Degree

\begin{tabular}{|c|c|c|c|c|}
\hline Sample & $\begin{array}{c}\text { Thickness } \\
(\mu \mathrm{m})\end{array}$ & $\begin{array}{c}\text { Density } \\
\left(\mathrm{g} / \mathrm{cm}^{3}\right)\end{array}$ & $\begin{array}{c}\text { Bulk } \\
\left(\mathrm{cm}^{3} / \mathrm{g}\right)\end{array}$ & $\begin{array}{c}\text { PPS Roughness } \\
(\mu \mathrm{m})\end{array}$ \\
\hline B-25 & 356.8 & 0.213 & 4.69 & 9.14 \\
\hline B-30 & 373.9 & 0.199 & 5.02 & 8.86 \\
\hline B-35 & 363.7 & 0.201 & 4.97 & 8.94 \\
\hline B-40 & 365.3 & 0.207 & 4.84 & 8.79 \\
\hline B-45 & 352.4 & 0.211 & 4.75 & 8.66 \\
\hline B-50 & 338.9 & 0.216 & 4.63 & 8.74 \\
\hline B-55 & 335.0 & 0.223 & 4.48 & 8.63 \\
\hline B-60 & 329.9 & 0.229 & 4.37 & 8.62 \\
\hline
\end{tabular}
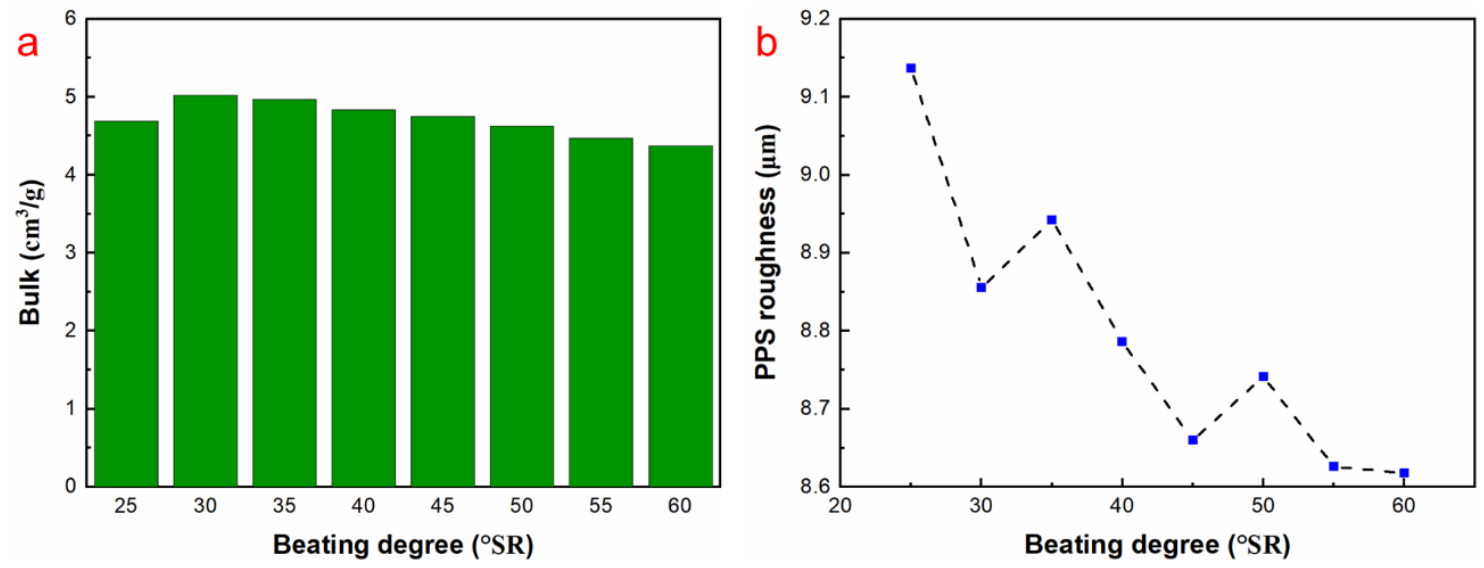

Fig. 4. Bulk (a) and PPS roughness (b) of polylactic acid composite papers made from pulp content of 7:3 (polylactic acid fiber : wood fiber) 
As shown in Fig. 4a, the roughness of the composite papers possessed a decreasing tendency as the beating degree of the wood fiber increased. Additionally, the value of roughness finally encountered a limitation at $8.6 \mu \mathrm{m}$ as its decreasing rate slowed down when the beating degree of wood fiber approached $60{ }^{\circ} \mathrm{SR}$.

It is possible that as the beating degree increases, the wood fibers will experience swelling and fibrillation thus becoming more flexible, and be cut into fragments, showing a larger specific surface area and exposing more hydroxyl groups on the surface (Page 1989). Such changes are conducive to fiber entanglement and hydrogen bonding. The wood fiber in the composite paper is able to form a more compact network and a smoother surface. Moreover, the cellulosic fines produced during the beating can also fill the interspaces between polylactic acid fibers. Therefore, as shown above, the bulk and surface roughness of papers are expected to decrease when the beating degree increases. The mechanical properties of the composite papers made from wood fibers with different beating degrees are shown in Table 6, including tensile strength, tensile index, and folding endurance.

Table 6. Tensile Strength, Tensile Index, and Folding Endurance of the Composite Papers Made from 30 wt\% Wood Fiber with Different Beating Degree

\begin{tabular}{|c|c|c|c|}
\hline Sample & $\begin{array}{c}\text { Tensile Strength } \\
(\mathrm{N} / \mathrm{m})\end{array}$ & $\begin{array}{c}\text { Tensile Index } \\
(\mathrm{N} \cdot \mathrm{m} / \mathrm{g})\end{array}$ & $\begin{array}{c}\text { Folding Endurance } \\
\text { (times) }\end{array}$ \\
\hline B-25 & 645 & 8.49 & 0.50 \\
\hline B-30 & 700 & 9.42 & 0.67 \\
\hline B-35 & 706 & 9.65 & 0.50 \\
\hline B-40 & 748 & 9.96 & 0.83 \\
\hline B-45 & 751 & 10.2 & 0.67 \\
\hline B-50 & 806 & 11.0 & 0.83 \\
\hline B-55 & 836 & 11.1 & 1.17 \\
\hline B-60 & 882 & 11.7 & 1.17 \\
\hline
\end{tabular}

As demonstrated in Fig. 5a, the tensile index performed linearly, increasing as the beating degree of wood fiber changed from 25 to $60{ }^{\circ} \mathrm{SR}$. When the beating degree of wood fiber reached $60{ }^{\circ} \mathrm{SR}$, the tensile index of composite paper was improved $37.9 \%$ compared with that of composite paper made from $25{ }^{\circ} \mathrm{SR}$ wood fiber. Linear regression was implemented and the results are shown in Table 7.
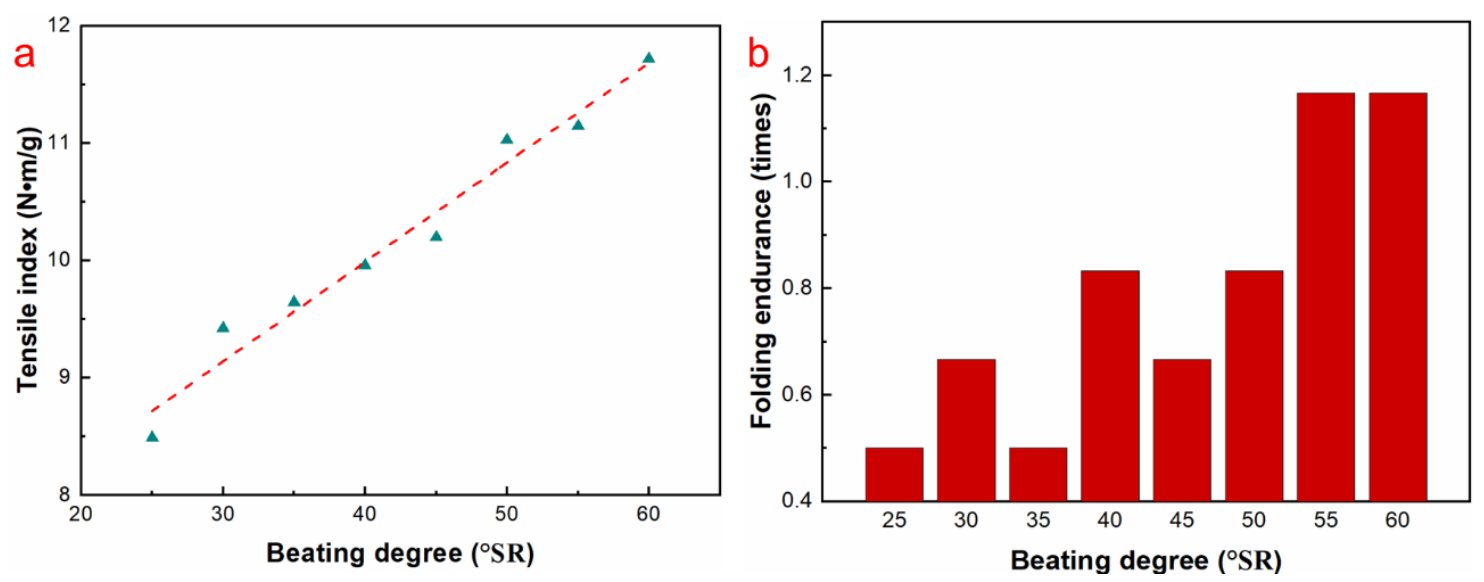

Fig. 5. Tensile index (a) and folding endurance (b) of polylactic acid composite papers made from pulp content of 7:3 (polylactic acid fiber : wood fiber) 
Table 7. Results of Linear Regression Analysis of Tensile Index

\begin{tabular}{|c|c|}
\hline $\begin{array}{c}\text { Regression and } \\
\text { Coefficient of } \\
\text { Determination }\end{array}$ & Tensile Index \\
\hline $\mathrm{A}$ & 6.6007 \\
\hline $\mathrm{B}$ & 0.0847 \\
\hline $\mathrm{R}^{2}$ & 0.9698 \\
\hline
\end{tabular}

The folding endurance of the composite papers, which is shown in Fig. 5b, was slightly enhanced with the increased beating degree of wood fiber. This result is consistent with the previous related study (Hui et al. 2018). However, the folding endurance values of these composite papers were all less than 2 times because of the poor mechanical properties of the composite paper with this fiber furnish.

In conclusion, the increasing of beating degree holds a noticeably positive effect on the tensile index of the composite paper, and can improve the density, surface smoothness, and resistance to folding.

\section{Effect of Calendering on the Physical Properties of the Composite Paper}

For comparison, the physical properties of the composite paper before and after the calendering are listed in Table 8, including thickness, density, PPS roughness, tensile index, and folding endurance.

Table 8. The Effect of Calendering on the Physical Properties of the Composite Paper

\begin{tabular}{|c|c|c|}
\hline Physical Property & $\begin{array}{c}\text { Untreated Composite } \\
\text { Paper }\end{array}$ & $\begin{array}{c}\text { Calendered Composite } \\
\text { Paper }\end{array}$ \\
\hline Thickness $(\mu \mathrm{m})$ & 197.4 & 126.5 \\
\hline Density $\left(\mathrm{g} / \mathrm{cm}^{3}\right)$ & 0.392 & 0.628 \\
\hline PPS Roughness $(\mu \mathrm{m})$ & 7.29 & 3.95 \\
\hline Tensile Index $(\mathrm{N} \bullet \mathrm{m} / \mathrm{g})$ & 14.48 & 16.73 \\
\hline Folding Endurance $($ times $)$ & 5.4 & 13.4 \\
\hline Air Permeability $(\mathrm{mL} / \mathrm{min})$ & 6103 & 1260 \\
\hline
\end{tabular}

Table 8 shows that the density of the composite paper increased $60.2 \%$ as the paper thickness reduced from 197.4 to $126.5 \mu \mathrm{m}$. The roughness decreased $45.8 \%$, while the tensile index and folding endurance increased $15.5 \%$ and $148.1 \%$, respectively. In addition, the air permeability dropped from 6103 to $1260 \mathrm{~mL} / \mathrm{min}$, a decrease of $79.4 \%$. In sum, the calendering process greatly improved the density, smoothness, folding endurance and air barrier property of the composite paper, and mildly enhanced the tensile index.

These changes in the physical properties of the composite paper are consistent with previous studies (Yang et al. 2019; Raunio et al. 2020). In these studies, it was found that polylactic acid fibers can fill the pores and gaps in the paper due to heat conduction and pressure, thereby improving the density and mechanical properties of the composite paper. As the composite papers were densified during the process of calendering, the paths crossing the paper in the Z-direction were closed or became more tortuous, enduing the paper with a better air barrier property. 


\section{SEM Analysis of the Composite Papers}

Figure $7 \mathrm{a}$ through $7 \mathrm{~h}$ show the SEM images of composite papers made of $10 \mathrm{wt} \%$, $40 \mathrm{wt} \%, 50 \mathrm{wt} \%$, and $70 \mathrm{wt} \%$ wood fibers under two magnifications.

As shown in Fig. 6a and 6b, the surface of polylactic acid fiber was smooth, and even though some polylactic acid fibers entangled together, the attraction and adhesion between them were relatively weak. The polylactic acid fibers were far apart from each other, and the composite papers with high polylactic acid fiber content were full of pores. Additionally, as shown in Fig. 6c through $6 \mathrm{~h}$, the beaten softwood fibers exhibited excellent flexibility, and interweaved with polylactic acid fibers to form the thin fiber layers that were smoother and less porous. The SEM images of composite papers consisting of different amount of wood fibers were compared, it can be concluded that the introduction of wood fibers filled the pores and gaps between the polylactic acid fibers, which accounts for the improvement in the density and smoothness of composite papers.

During the process of beating, the wood fibers were subjected to stress and shear forces, causing the deformation and removal on the cell wall (Willison and Brown, Jr. 1977). These effects can be clearly observed in Figs. 6d, 6f, and 6h, where the wood fibers' surfaces are rough, profiles are fuzzy, and many microfibers extend from the body of the fibers. In addition to enhancing the interactions among the wood fibers, these fibrillated, fine, and flexible microfibers wrapped around the brittle polylactic acid fiber like a spider web, which is demonstrated in Fig. 6d and 6f. These microfiber webs and the polylactic acid fibers being wrapped can combine together through hydrogen bonding, Van der Waals force, and friction force. Therefore, when the composite paper is stretched or torn by external force, the local stress can be dispersed to the surroundings via this network structure, which explains the increase in the physical strength of the composite paper.

Figures $6 \mathrm{i}$ and $6 \mathrm{j}$ are the SEM images of the calendered composite paper surface morphology under different magnification, respectively. Calendering is a finishing operation in the papermaking industry to enhance the smoothness and gloss of the final paper, which produces a permanent deformation on the fiber and paper (Rättö 2002; Gupta and Kanth 2019). These effects can be clearly observed in Fig. 6i, where the polylactic acid fibers and wood fibers were compressed to a flat shape and stacked compactly, forming a level and smooth plate layer on the paper surface. This transformation that happened on the composite paper surface is consistent with results of a previous study (Raunio et al. 2020). In the study, it was found that polylactic acid fibers deform, melt, and flow around the plant fibers during the thermoforming treatment. The melted polylactic acid finally forms a film into the sheet's structure and fills the pores in the paper. Therefore, the calendering process can impart a denser structure and better mechanical strength to the composite paper.

However, it should be noted that some fractures on polylactic acid fibers can be induced by calendaring (Fig. 6j). These fractures might be due to the rolling calender method adopted in this study, and the relatively low roll temperature $\left(130^{\circ} \mathrm{C}\right)$ compared with the polylactic acid melting point $\left(157.2^{\circ} \mathrm{C}\right)$. In calendering, the round sheets of composite paper with a diameter of $160 \mathrm{~mm}$ passed through the nip in less than $0.5 \mathrm{~s}$. For a single polylactic acid fiber in the composite paper, the contact with rolls lasted even shorter. When polylactic acid fibers are heated up to a temperature greater than its $T_{\mathrm{g}}$, it will change from a glassy state to a rubbery state with a dropping storage modulus (Larsson et al. 2012), making itself more prone to plastic deformation. 


\section{bioresources.com}
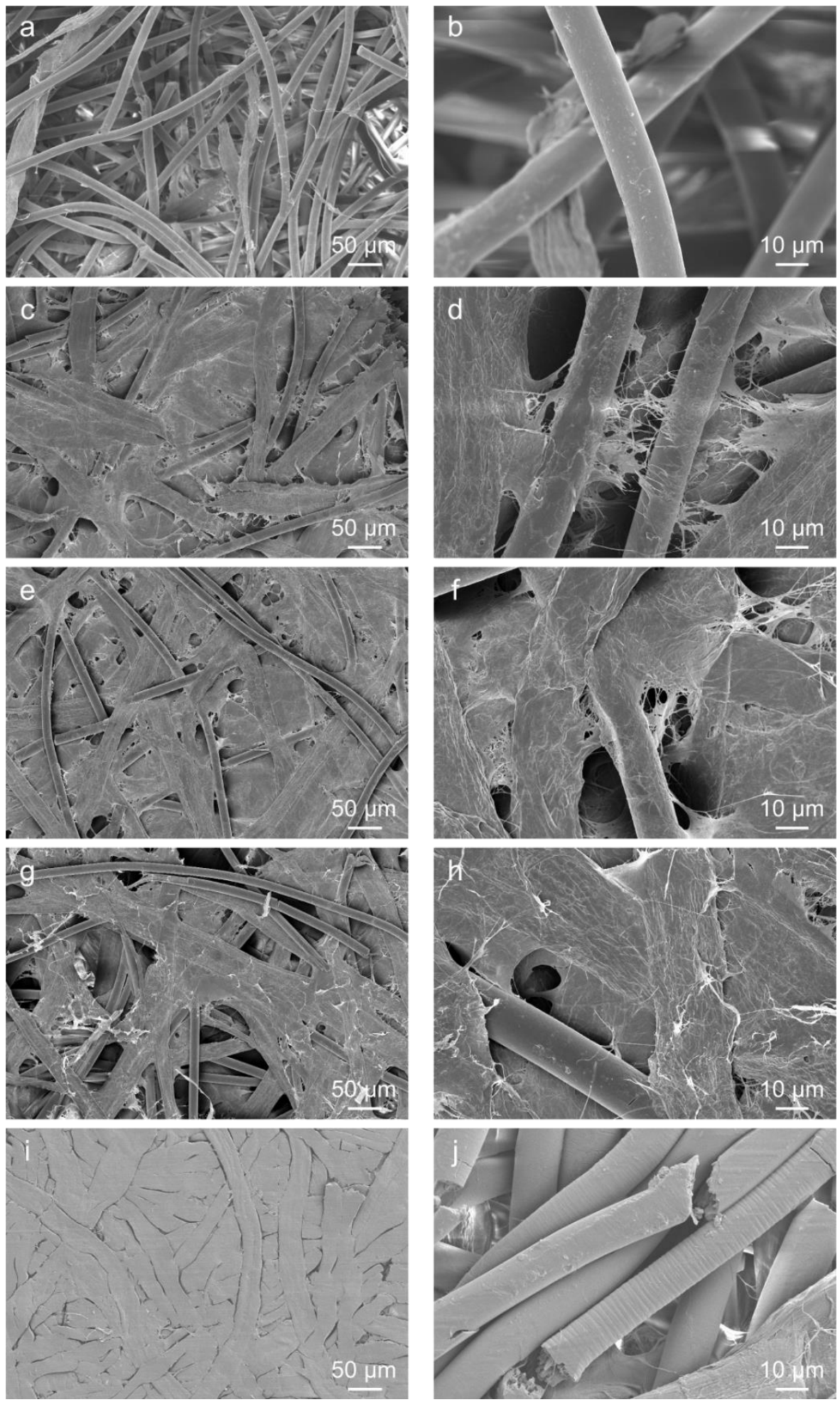

Fig. 6. SEM images of composite papers: a) composite paper made of $10 \mathrm{wt} \%$ wood fibers $(\times 200)$; b) composite paper made of $10 \mathrm{wt} \%$ wood fibers $(\times 1000)$; c) composite paper made of 40 wt\% wood fibers $(\times 200)$; d) composite paper made of $40 \mathrm{wt} \%$ wood fibers $(\times 1000)$; e) composite paper made of 50 wt $\%$ wood fibers $(\times 200)$; f) composite paper made of 50 wt $\%$ wood fibers $(\times 1000) ; g)$ composite paper made of $70 w \%$ wood fibers $(\times 200) ; \mathrm{h})$ composite paper made of 70 wt $\%$ wood fibers ( $\times 1000)$; i) calendered paper made from 50 wt $\%$ wood fibers $(\times 200)$; j) calendered paper made from $50 \mathrm{wt} \%$ wood fibers $(\times 1000)$ 
However, because of the relatively low roll temperature and limited contact time, the polylactic acid fibers in the interior of paper cannot obtain enough heat through heat conduction to heat up to a temperature exceeding $T_{\mathrm{g}}$. These polylactic acid fibers, which are glassy, brittle, and lacking in plasticity, bore the pressure imposed by the rolls, and some of them finally fractured.

The fracture of polylactic acid fiber reduces the polylactic acid fiber length, which has a negative impact on the tensile strength. Based on the improved paper density and the fracture of polylactic acid fiber, it might be reasonable to infer that the density, smoothness, folding endurance, and tensile index of the composite paper increase after calendering, while the tensile index shows a smaller increase magnitude compared with others.

To gain a better insight into the effect of roll calendering on the structure and mechanical properties composite paper, further research should be conducted to investigate the physical properties of calendered composite paper under different calendering conditions.

\section{ACKNOWLEDGMENTS}

The authors are grateful for the support from the Grant 2020XY03.

\section{CONCLUSIONS}

1. The introduction of wood fiber into polylactic acid paper by a calendering-based papermaking method led to remarkable improvements in the density, smoothness, tensile strength, and folding endurance of the polylactic acid paper.

2. The density, smoothness, tensile strength, and folding endurance of composite paper increased with the amount and beating degree of wood fiber.

3. Calendered composite papers exhibited higher density, folding endurance, tensile index, surface smoothness, and air barrier property (increased 60.2\%, 148.1\%, 15.5\%, 45.8\%, and $79.4 \%$ respectively), compared with the un-calendered ones. The SEM image indicated that some fractures on polylactic acid fibers can be induced by this process.

\section{REFERENCES CITED}

Akinbade, Y., and Harries, K. A. (2021). "Is the rule of mixture appropriate for assessing bamboo material properties?," Construction and Building Materials 267(18), article ID 120955. DOI: 10.1016/j.conbuildmat.2020.120955

Cao, X., and Chen, G. (2010). "Studies on beating and papermaking performance of PLA fibers," China Pulp \& Paper Industry 31(4), 32-36. DOI: 10.3969/j.issn.10079211.2010.04.006

Gupta, N., and Kanth, N. (2019). "Study of heat conduction inside rolling calender nip for different roll temperatures," in: Journal of Physics: Conference Series, Dubai, UAE, pp. 012044-012052. 
Hubbe, M. A. (2006). "Bonding between cellulosic fibers in the absence and presence of dry-strength agents - A review," BioResources 1(2), 281-318. DOI: 10.15376/biores.1.2.Hubbe

Hui, L., Yang, B., Han, X., and Liu, M. (2018). "Application of synthetic fiber in air filter paper," BioResources 13(2), 4264-4278. DOI: 10.15376/biores.13.2.4264-4278

ISO 5636-5 (2013). "Paper and board determination of air permeance (medium range)," International Organization for Standardization, Geneva, Switzerland.

Jamshidian, M., Tehrany, E. A., Imran, M., Jacquot, M., and Desobry, S. (2010). "Polylactic acid: Production, applications, nanocomposites, and release studies," Comprehensive Reviews in Food Science and Food Safety 9(5), 552-571. DOI: 10.1111/j.1541-4337.2010.00126.x

Lau, W. W., Shiran, Y., Bailey, R. M., Cook, E., Stuchtey, M. R., Koskella, J., Velis, C., Godfrey, L., Boucher, J., Murphy, M., et al. (2020). "Evaluating scenarios toward zero plastic pollution," Science 369(6510), 1455-1461. DOI: 10.1126/science.aba9475

Larsson, K., Berglund, L. A., Ankerfors, M., and Lindström, T. (2012). "Polylactide latex/nanofibrillated cellulose bionanocomposites of high nanofibrillated cellulose content and nanopaper network structure prepared by a papermaking route," Journal of Applied Polymer Science 125(3), 2460-2466. DOI: 10.1002/app.36413

Lindsay, J. D., and Brady, P. H. (1993). "Studies of anisotropic permeability with applications to water removal in fibrous webs. Part 1," TAPPI Journal 76(9), 119127.

Nagarajan, V., Mohanty, A. K., and Misra, M. (2016). "Perspective on polylactic acid (PLA) based sustainable materials for durable applications: Focus on toughness and heat resistance," ACS Sustainable Chemistry \& Engineering 4(6), 2899-2916. DOI: 10.1021/acssuschemeng.6b00321

Naithani, V., Tyagi, P., Jameel, H., Lucia, L. A., and Pal, L. (2020). “Ecofriendly and innovative processing of hemp hurds fibers for tissue and towel paper," BioResources 15(1), 706-720. DOI: 10.15376/biores.15.1.706-720

Nakagaito, A., Fujimura, A., Sakai, T., Hama, Y., and Yano, H. (2009). "Production of microfibrillated cellulose (MFC)-reinforced polylactic acid (PLA) nanocomposites from sheets obtained by a papermaking-like process," Compos Sci Technol 69(7-8), 1293-1297. DOI: 10.1016/j.compscitech.2009.03.004

Page, D. H. (1989). "The beating of chemical pulp-the action and effect," in: 9th Fundamental Research Symposium, Cambridge, UK, pp. 1-38.

Rättö, P. (2002). "Description and analysis of paper deformation in a calender nip-effects of high roll temperatures and thickness variations," Nordic Pulp \& Paper Research Journal 17(2), 130-138. DOI: 10.3183/npprj-2002-17-02-p130-138

Raunio, J., Asikainen, T., Wilo, M., Kallio, E., and Csóka, L. (2020). "Affecting the bonding between PLA fibrils and kraft pulp for improving paper dry-strength," Nordic Pulp \& Paper Research Journal 35(2), 185-194. DOI: 10.1515/npprj-20190033

Rungiah, S., Ruamsuk, R., Vroman, P., Takarada, W., Appert-Collin, J. C., and Kikutani, T. (2017). "Structural characterization of polypropylene/poly (lactic acid) bicomponent meltblown," Journal of Applied Polymer Science 134(14), article ID 44540. DOI: 10.1002/app.44540 
Singhvi, M. S., Zinjarde, S. S., and Gokhale, D. V. (2019). "Polylactic acid: Synthesis and biomedical applications," Journal of Applied Microbiology 127(6), 1612-1626. DOI: $10.1111 /$ jam.14290

Sousa, S., Costa, A. P., and Simões, R. (2019). "Poly (lactic acid) composites reinforced with kraft pulp fibres: Production by a papermaking process and characterisation," Composites Part A: Applied Science and Manufacturing 121, 273-282. DOI: 10.1016/j.compositesa.2019.03.024

TAPPI T205 sp-18 (2018). "Forming hand sheets for physical tests of pulp," TAPPI Press, Atlanta, GA, USA.

TAPPI T248 sp-00 (2000). "Laboratory beating of pulp (PFI mill method)," TAPPI Press, Atlanta, GA, USA.

TAPPI T404 wd-03 (2003). "Tensile strength tests of paper and paperboard," TAPPI Press, Atlanta, GA, USA.

TAPPI T511 om-13 (2013). "Folding endurance of paper (MIT tester)," TAPPI Press, Atlanta, GA, USA.

TAPPI T555 om-99. (1999). "Roughness of paper and paperboard (print-surf method)," TAPPI Press, Atlanta, GA, USA.

Tyagi, P., Mathew, R., Opperman, C., Jameel, H., Gonzalez, R., Lucia, L., Hubbe, M. A., and Pal, L. (2018). "High-strength antibacterial chitosan-cellulose nanocrystal composite tissue paper," Langmuir 35(1), 104-112. DOI: 10.1021/acs.langmuir.8b02655

Venkateshwaran, N., Elayaperumal, A., and Sathiya, G. K. (2012). "Prediction of tensile properties of hybrid-natural fiber composites," Composites Part B: Engineering 43(2), 793-796. DOI: 10.1016/j.compositesb.2011.08.023

Wang, R., Yang, R., and Yang, F. (2015). "Production of bamboo fiber reinforced fibrillated poly(lactic acid)(PLA) Material Obtained by a Papermaking Process," Journal of Wuhan University of Technology 30(2), 429-432. DOI: 10.1007/s11595015-1165-y

Willison, J. H. M., and Brown, Jr., R. M. (1977). "An examination of the developing cotton fiber: Wall and plasmalemma," Protoplasma 92(1), 21-41. DOI: 10.1007/BF01280198

Yang, D., Hu, H., Pan, G., Ma, B., and Hou, X. (2019). "Preparation and properties of flexible cotton stalk bark fibers/PLA composite," Plastic 48(1), 7-15. DOI: $10.2307 / 474728$

Yang, F., Ma, H., Tang, L., and Feng, Y. (2018). "Effect of polyvinyl alcohol treatment on mechanical properties of bamboo/polylactic acid composites," BioResources 13(2), 2578-2591. DOI: 10.15376/biores.13.2.2578-2591

Zambrano, F., Starkey, H., Wang, Y., Abbati de Assis, C., Venditti, R., Pal, L., Jameel, H., Hubbe, M. A., Rojas, O. J., and Gonzalez, R. (2020). "Using micro- and nanofibrillated cellulose as a means to reduce weight of paper products: A review," BioResources 15(2), 4553-4590. DOI: 10.15376/biores.15.2.Zambrano

Article submitted: June 15, 2021; Peer review completed: September 18, 2021; Revised version received and accepted: October 22, 2021; Published: October 26, 2021.

DOI: $10.15376 /$ biores.16.4.8258-8272 